Journal of Applied Fluid Mechanics, Vol. 9, Special Issue 2, pp. 213-222, 2016.

Selected papers from the XIIth Franco - Quebec Inter-University

Symposium on Thermal Systems -2015

Available online at www.jafmonline.net, ISSN 1735-3572, EISSN 1735-3645.

DOI: $10.36884 /$ jafm.9.SI2.25776

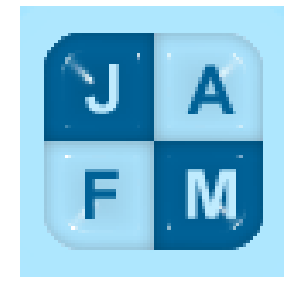

\title{
Analysis of the Critical Conditions and the Effect of Slip in Two-Phase Ejectors
}

\author{
K. Ameur ${ }^{\dagger}$, Z. Aidoun and M. Ouzzane \\ Canmet ENERGY, Natural Resources Canada, Varennes, Qc, J3X1S6, Canada \\ †Corresponding AuthorEmail: khaled.ameur@canada.ca
}

(Received October 8, 2015; accepted December 10, 2015)

\begin{abstract}
In this study, it is proposed to lift the no-slip constraint imposed in the Homogenous equilibrium Model (HEM) for two-phase ejector design and analyse its effects on performance. Two models accounting for slip are used: the first, currently available in the literature is due to Moody and the second, developed by the authors is proposed as an alternative. Firstly, in order to avoid the direct computation of the velocity of sound in two-phase flow close to critical conditions, it is proposed to maximise the mass flow rate in the nozzle without recourse to the Mach number, since the computation of this latter in two-phase conditions has not yet gained consensus. Secondly, the introduction of a slip factor accounting for the velocity difference between vapour and liquid phases has allowed achieving remarkable improvements of critical flow computations, especially when using the newly developed approach by the authors. Thirdly a test facility for two-phase ejectors using R134a as refrigerant has been built for further studies. First results have allowed to validate the models predictions of the critical flow over a large interval of operating conditions. Lastly, analysis indicates that neglecting interphase slip may have a significant impact on two-phase ejector design. In this way and under some ejector inlet conditions, the prediction gap between HEM and the new model falls in the range of 13 to $23 \%$ in terms of compression ratio and in the range of 33 to $39 \%$ for the nozzle throat diameter.
\end{abstract}

Keywords: Two-phase ejector; Critical flow; Modeling; Slip flow; Experiments.

\section{NOMENCLATURE}

surface
diameter
mass flux
enthalpy
length
mass flow rate
pressure
slip factor
temperature
velocity
volume
vapour mass fraction
void fraction
isentropic exponent
difference
isentropic efficiency
specific volume

\section{INTRODUCTION}

An ejector is a jet device, activated by low quality heat sources in its single phase version (vapourvapour) or by potential energy if the ejector is two-

$\begin{array}{ll}\tau & \text { compression ratio } \\ \varphi & \text { mixing coefficient, angle } \\ \omega & \text { entrainment ratio } \\ \text { subscript: } \\ 0 & \text { stagnation } \\ \text { crit } & \text { critical } \\ \text { dif } & \text { diffuser } \\ \text { is } & \text { isentropic } \\ 1 & \text { liquid } \\ \mathrm{m} & \text { mixture } \\ \text { max } & \text { maximum } \\ \text { prim } & \text { primary } \\ \text { sat } & \text { saturated } \\ \text { sec } & \text { secondary } \\ \mathrm{t} & \text { throat } \\ \mathrm{V} & \text { vapour }\end{array}$

phase (liquid-vapour).

It is a static device in which a supersonic expansion of a motive stream (primary flow) at relatively high pressure and temperature is induced inside a nozzle in such a way that it draws a lower energy flow 
generally subsonic (secondary flow). The resulting mixture is globally supersonic and undergoes a first pressure increase in the mixing chamber during a process of stream interaction with shock waves formation. Mixed, subsonic flow resulting from this phase is further compressed in the diffuser following the mixing chamber. Ejector is commonly used to draw, compress or mix fluids and its potential applications are diverse.

Refrigeration and air conditioning are the most obvious applications but several other potential applications may be thought of in industry, such as separation of vapours, solvents, chemical products and fumes. An application of two-phase ejectors which has attracted the interest of many researchers in the last decade is the replacement of the expansion valve in the conventional compression cycle for refrigeration and air conditioning. It is expected to reduce expansion losses occurring in the valve during the isenthalpic process undergone by the refrigerant liquid between the condenser and the evaporator. Even though modest, the ejector is also expected to provide some compression between the evaporator and the compressor suction. The end result is an overall performance improvement of the mechanical compression cycle.

A literature review has shown that thermodynamic modeling methods are the most widespread for twophase ejector design. The main asset of these methods resides in their relative simplicity and their speed in generating results. (Kornhauser 1990) put together one of the first thermodynamic models for the design of ejectors operating as expanders. His approach relied on the HEM model which assumes a constant pressure mixing of the primary and secondary streams. Isentropic coefficients were used in order to account for the losses due to friction in the primary nozzle and the diffuser. The Kornhauser model has since been used by many researchers and remains attractive thanks to its simplicity. Nevertheless, the thermodynamic approach has also its weaknesses. For example, selecting isentropic coefficients may be tricky, particularly in two-phase conditions where flow configurations are generally complex and few practical data and information are available (Domanski 1995).

In this context several researchers have set such coefficients at values markedly lower than those usually employed for single phase ejector design. It is typically the case in the work of (Lawrence \& Elbel 2012) who used efficiency coefficients in the primary nozzle and the diffuser of 0.8 and 0.75 , respectively.

On the basis of a thermodynamical model and experimental results obtained on an ejector working with $\mathrm{CO}_{2}$ in transcritical conditions, (Liu and Groll 2013) have also shown that isentropic coefficients in primary and secondary models, as well as the loss factor commonly used in the mixing chamber could widely vary depending on ejector geometry and operating conditions (typically between 0.5 $0.93,0.37-0.9$ and $0.5-1.0$ respectively

Among the weaknesses of the Kornhauser model, the probable formation of shock waves in the mixing chamber is not accounted for, which may induce important uncertainties in the results predictions. This model in its initial version introduces another simplification making impossible an optimal design of the ejector, since no adequate provision is made in the computations for critical flow in the nozzles.

Some researchers like (Nakagawa et al. 1996) did attempt to improve on the Kornhauser model by proposing a hybrid approach based on thermodynamic and 1-D modeling. In their development, the efficiency of the primary nozzle is accounted for by means of the isentropic coefficient concept while a 1-D treatment is applied to the remainder of the ejector.

In this approach, the conservation of momentum is applied on both liquid and vapour phase and a coefficient of friction is applied only to the vapour phase which is assumed to be the only in contact with the wall. A similar method was adopted by (Banasiak and Hafner 2011) who used the thermodynamic approach in the mixing chamber and the other ejector zones were handled by means of 1-D treatment.

In yet another model proposed by (Liu \& Groll 2008) and relying on the HEM concept, critical flow is accounted for and computed in the primary nozzle by satisfying sonic conditions at the throat. The equation used for the sonic conditions is due to (Attou and Seynhaeve 1999). In order to account for losses in the mixing chamber a mixing factor is included in the momentum equation representing the flow. Pressure variation in the diffuser is determined by means of a recovery factor resulting from an experimental correlation established for a limited range of flow conditions.

In the present contribution, further steps have been taken to extend on the previous work.

A new model is proposed with the intent of lifting two important constraints generally encountered in previous works as shown above. The first constraint concerns the evaluation of the critical flow in twophase conditions and the second relates to the no slip assumption characterizing the HEM model. The critical flow in the primary nozzle throat where local nucleation occurs is obtained by flow maximisation. This approach permits to get round the direct computation of the sound velocity, a parameter usually being the main criterion in qualifying critical flow conditions when only one phase is present. Unfortunately in two-phase conditions the velocity of sound determination is, to the best of our knowledge still approximate.

The HEM no slip assumption is lifted in its turn by introducing a slip factor which takes into account the velocity difference between vapour and liquid phases. In this context, two slip models are introduced and compared against the classical HEM: a model often encountered in the literature due to (Moody 1965) and the newly proposed by the authors.

A test bench for two-phase ejectors has been built in Canmet ENERGY-Varennes Laboratories. A first series of data has been used for models validation of the critical flow presented in this article. Further data has been generated to perform a preliminary 
analysis of the effect of the mechanical equilibrium assumption on ejector design. Quantifying such a simplifying assumption has been achieved based on these results.

\section{EJECTOR MODEL}

The two-phase ejector model developed here is based on a thermodynamic approach, where inlets and outlets to different zones of the ejector are represented in Fig. 1a. It is integrated in a refrigeration cycle as indicated in Fig. 1b which shows a typical application of the two-phase ejector as an expander device.

The homogeneous two-phase flow model where vapour and liquid phases are in dynamic and thermal equilibrium has first served as a basis for the determination of thermodynamic properties. Equations for heat, mass and momentum transfers have be formulated according to this assumption. In this way the vapour and liquid combined flow is considered to behave like a single phase with a unique temperature, pressure and velocity. Moreover the flow is assumed to be steady with the properties varying only in axial direction. In addition the following approximations have been used:

- Adiabatic flow.

- Stagnation conditions in both primary and secondary inlets.

- Wall friction in the nozzles and the diffuser accounted for by means of isentropic efficiency factors.

- Mixing losses estimated on the basis of momentum exchange between primary and secondary streams.
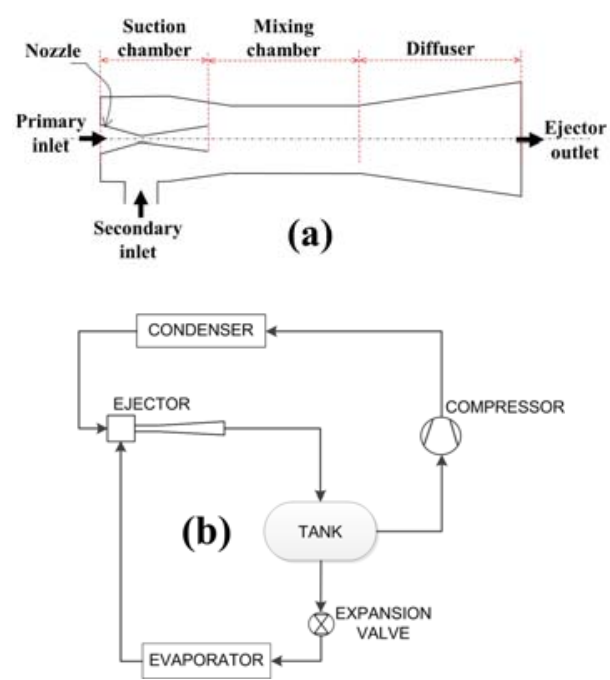

Fig. 1. Two-phase ejector: (a) simplified schema of the ejector and (b) ejector as expander in a refrigeration cycle.

The main equations governing the flow are those of mass, energy and momentum. Flow thermophysical properties for real fluids are obtained by coupling REFPROP subroutines (NIST 2007) to the ejector custom program written in FORTRAN. For more details on this modeling, the reader is referred to (Ameur et al. 2014).

\subsection{Sound Speed Issue}

The speed of sound is used to calculate the Mach number which is an important parameter in the evaluation of the critical flow. For single phase flows this method of calculation is the most used and straightforward. Maximum flow in the nozzle is generally obtained when sonic conditions are reached at the throat. For single phase flow, the link between the critical flow and the velocity of sound is easily established. In two-phase flow conditions however, the velocity of sound becomes more difficult to evaluate, especially if the two phases present wide differences in velocity and temperature (Michaelides and Zissis 1983). This evaluation becomes even more uncertain as the liquid saturation line is approached and where the variation of most parameters exhibits strong gradients. In order to circumvent this obstacle a mass flux maximisation condition was applied at the nozzle throat, so that the critical flow could be determined as:

$\left(\frac{\partial G}{\partial P}\right)_{t}=0$

\subsection{Critical Flow in the Nozzle}

By using the mass flow maximisation for critical flow at the nozzle throat, three models are presented in what follows.

\subsubsection{HEM model}

Homogeneous Equilibrium Model (HEM) serves as a standard model for critical flow in nozzles (Weisman and Tentner 1978) and to which the subsequent approaches in this work are compared. HEM is particularly appropriate when flow has sufficient time to achieve thermal equilibrium and certain flow patterns favoring small relative motion between phases, thus negligible slip between phases (Wallis 1980).

Mass and energy conservation equations are used to relate mass flow with enthalpy and density as

$G_{t}=(\bar{\rho} \bar{V})_{t}=\bar{\rho}_{t} \sqrt{2\left(\bar{h}_{0}-\bar{h}_{t}\right)}$

The mean density may be expressed as in terms of specific volume

$\bar{\rho}=\frac{1}{x v_{v}+(1-x) v_{l}}$

Then combining Eqs. 2 and 3 leads to

$G_{t}=\frac{\sqrt{2\left(\bar{h}_{0}-\bar{h}_{t}\right)}}{\left[x v_{v}+(1-x) v_{l}\right]_{t}}$ 
The expansion in the nozzles in practice is not ideal. Incurred enthalpy losses at the throat are taken into account by an isentropic efficiency coefficient, such that:

$$
\bar{h}_{t}=\bar{h}_{0}-\eta\left(\bar{h}_{0}-\bar{h}_{t_{i s}}\right)
$$

Equation (4) above being non linear, the solution of Eq. (1) cannot be obtained analytically and therefore the mass flux maximisation at the throat is computed numerically.

\subsubsection{Moody model}

In the above model the mechanical non equilibrium existing between liquid and vapour phases is not accounted for. In two-phase flow however, this can considerably underestimate the critical mass flux (Moody 1965). Slip flow between phases was introduced for this purpose and constitutes an extension to the HEM model in which phase velocities are no longer equal.

It is first assumed that the mean velocity is expressed by:

$\bar{V}=x V_{v}+(1-x) V_{l}$

A slip factor between phases is defined as:

$S=\frac{V_{v}}{V_{l}}$

And then, combining energy and mass conservation equations leads after some algebraic manipulation to mass flux expression as:

$$
G_{t}^{2}=\frac{2\left(\bar{h}_{0}-\bar{h}_{t}\right)}{\left\{\left[\frac{1-x}{\rho_{l}}+\frac{x}{\rho_{v} S}\right]^{2}\left[x S^{2}+(1-x)\right]\right\}_{t}}
$$

Following a similar procedure to the case with no slip, the critical mass flow is obtained by maximizing the flux except that in this case, two parameters are involved in the maximization process that is the pressure and the slip factor. (Moody 1965) in his procedure based on energy and mass conservation equation obtained the following expression:

$$
S=\left(\frac{\rho_{v}}{\rho_{l}}\right)^{1 / 3}
$$

\subsubsection{Proposed Slip Model}

In the proposed version of the slip model, the momentum and the mass conservation equations are used instead, given that the flow configuration involves phase velocity difference which naturally leads to some sort of momentum exchange between streams. Besides, the procedure demanded little mathematical manipulation.

The momentum equation is written as: $d P+\bar{\rho} \bar{V} d \bar{V}=0$

With $G=\bar{\rho} \bar{V}$ and the mean velocity given by Eq. (6), Eq. (10) then becomes:

$$
G d\left[x V_{v}+(1-x) V_{l}\right]=-d p
$$

This expression is derived with respect to pressure, keeping in mind (Eq. 1) for the critical flow, which leads to:

$G_{t} \frac{d}{d p}\left[x V_{v}+(1-x) V_{l}\right]=-1$

Now, the vapour mass flux is expressed by the following equation:

$\frac{m_{v}}{A_{v}}=\frac{x m}{\alpha A}=\rho_{v} V_{v}$

which in terms of the overall mass flux definition

$\frac{m}{A}=G$

results in the form:

$V_{v}=\frac{x}{\alpha} v_{v} G$

Similarly for the liquid phase, the following expression is obtained:

$\frac{m_{l}}{A_{l}}=\frac{(1-x) m}{(1-\alpha) A}=\rho_{l} V_{l}$

Combining again Eq. (14) and Eq. (16), the following expression is obtained for the liquid phase:

$$
V_{l}=\frac{(1-x)}{(1-\alpha)} v_{l} G
$$

Combining Eq. (9), Eq. (15) and Eq. (17) results in the expression for the slip factor:

$S=\frac{x}{\alpha} \frac{(1-\alpha)}{(1-x)} \frac{v_{v}}{v_{l}}$

The void fraction is extracted from Eq. (18) as,

$$
\alpha=\frac{x v_{v}}{S(1-x) v_{l}+x v_{v}}
$$

Replacing Eqs. (15, 17 and 19) in Eq. (12),

$G_{t} \frac{d}{d p}\left\{G\left[S(1-x) v_{l}+x v_{v}\right]\left(x+\frac{1-x}{S}\right)\right\}=-1$

Equation (20) is transformed to yield successively:

$$
-\frac{1}{G_{t}^{2}}=\frac{d}{d p}\left\{\frac{\left[S(1-x) v_{l}+x v_{v}\right][S x+(1-x)]}{S}\right\}
$$


and finally,

$$
-\frac{1}{G_{t}^{2}}=\left\{\begin{array}{l}
(1-x)[S x+(1-x)] \frac{d y}{d P} \\
+\frac{x}{S}[S x+(1-x)] \frac{d v_{v}}{d P} \\
+\left(v_{l}-\frac{v_{v}}{S^{2}}\right)(1-x) x \frac{d S}{d P} \\
+\left\{\frac{(S-1)}{S}\left[v_{l} S+x\left(v_{v}-v_{l} S\right)\right]+\left(v_{v}-v_{l} S\right) \frac{x(S-1)+1}{S}\right\} \frac{d x}{d P}
\end{array}\right)_{t}
$$

As it stands this expression is relatively complex but simplifying assumptions can be used. The following approximations can be considered:

- the liquid phase is incompressible $\left(\frac{d v_{l}}{d P}=0\right)$,

- slip is constant at the throat $\left(\frac{d S}{d P}=0\right)$,

- masse transfer is negligible $\left(\frac{d x}{d P}=0\right)$,

and Eq. (22) becomes:

$$
-\frac{1}{G_{t}^{2}}=\left\{\frac{x}{S}[S x+(1-x)] \frac{d v_{v}}{d P}\right\}_{t}
$$

The slip formulation, due to Chisholm (Collier \& Thome 1994) is:

$$
S=\left[1+x\left(\frac{\rho_{l}}{\rho_{v}}-1\right)\right]^{\frac{1}{2}}
$$

Equation (23) being coupled with the pressure at the throat, a second equation is required for the resolution. To this end the solution procedure suggested by (Henry and Fauske 1971) is selected. The momentum equation is integrated between the nozzle inlet and the throat. After some rearrangements, the following expression is obtained.

$$
G_{t}^{2}=2 \frac{v_{l 0}\left(1-x_{0}\right)\left(P_{0}-P_{t}\right)+\frac{x_{0} \gamma}{\gamma-1} v_{v 0} P_{0}^{\frac{1}{\gamma}}\left(P_{0}^{\frac{\gamma-1}{\gamma}}-P_{t}^{\frac{\gamma-1}{\gamma}}\right)}{\left[x_{0} v_{v t}+\left(1-x_{0}\right) v_{l 0}\right]^{2}}
$$

Solution of the system formed by Eqs. (23-25) requires iterative computations. Given the inlet conditions of the nozzle, a pressure range at the throat is swept over until both equations predict the mass flux within a pre-set error margin.

\section{EXPERIMENTAL SETUP}

In order to generate validation data for the theoretical model developed a test facility has been built to reproduce a wide range of ejector operating conditions. At the same time this gives the opportunity to understand further the overall ejector operation details and provide practical information. Figure 2 shows an overview of the set-up. Its nominal capacity is $5 \mathrm{~kW}$ approximately.

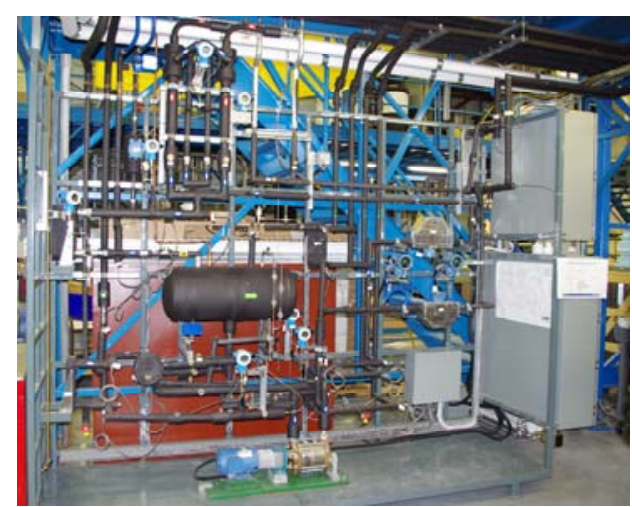

Fig. 2. Overall view of experimental set-up.

The test stand operates on refrigerant R134a and its main components are represented in Fig. 3. All heat exchangers are of brazed plate type and used in four auxiliary loops reproducing heat and source sinks. Each loop is fed either by water for cooling or preheating and by propylene-glycol on the cold sides for condensing and subcooling. A refrigeration unit with R507 is used to maintain these loops at the appropriate temperature levels. The test stand is well equipped with high quality instrumentation, more particularly around the ejector loop. The main measured parameters include temperatures, pressures, flow rates for vapour and liquid phases. Measurement uncertainties for all instruments are reported in Table 1. The main geometry specifications of the ejector are summarized in Table 2.

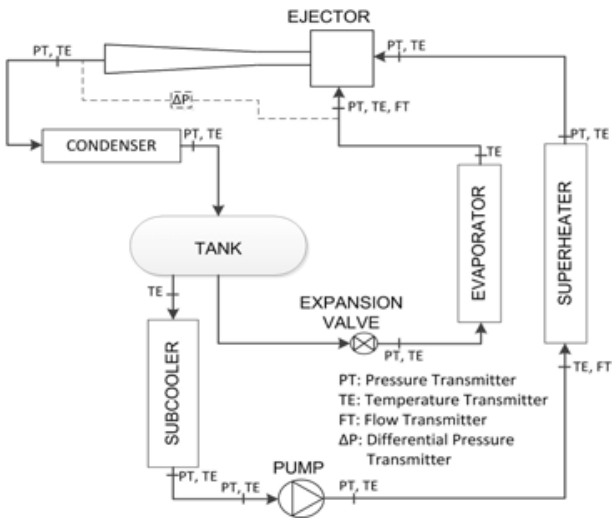

Fig. 3. Simplified diagram of the test bench.

Table 1: Measured parameters

\begin{tabular}{|l|l|}
\hline \multicolumn{1}{|c|}{ Measured parameters } & \multicolumn{1}{c|}{ Uncertainty } \\
\hline Temperature (RTD) & $\pm 0.05{ }^{\circ} \mathrm{C}$ \\
\hline $\begin{array}{l}\text { Pressure (Transducers with } \\
\text { metallic membrane) }\end{array}$ & $\pm 0.075 \%$ \\
\hline $\begin{array}{l}\text { Refrigerant mass flow rate } \\
\text { (Coriolis flow meter) }\end{array}$ & $\begin{array}{l} \pm 0.75 \% \text { Vapour } \\
\pm 0.3 \% \text { Liquid }\end{array}$ \\
\hline $\begin{array}{l}\text { Water-Glycol mass flow } \\
\text { rate (Magnetic flow meter) }\end{array}$ & $\pm 0.5 \%$ \\
\hline
\end{tabular}


Table 2: Ejector dimensions

\begin{tabular}{|c|l|c|c|}
\hline Section & Nozzle & Mixing & Diffuser \\
\hline$D(\mathrm{~mm})$ & $\begin{array}{l}\text { inlet: } 10 \\
\text { throat: } 1.39 \\
\text { outlet: } 4.09\end{array}$ & 6.98 & $\begin{array}{l}\text { in: } 6.98 \\
\text { out: } 31.8\end{array}$ \\
\hline$L(\mathrm{~mm})$ & $\begin{array}{l}\text { conv.: } 9.7 \\
\text { div.: } 38\end{array}$ & 164.31 & 134.26 \\
\hline$\varphi\left({ }^{\circ}\right)$ & $\begin{array}{l}\text { conv.: } 45 \\
\text { div.: } 4\end{array}$ & - & 11 \\
\hline
\end{tabular}

conv.: convergent, div.: divergent

The test bench has been designed to offer flexibility in parameters variation. Ejector inlet conditions can cover a wide temperature range $\left(10\right.$ to $60^{\circ} \mathrm{C}$ for the primary and -10 to $20^{\circ} \mathrm{C}$ for the secondary streams). The experimental results obtained in house and presented in this paper have been essentially used for validation purposes at the critical flow conditions of the primary stream. In view of the plurality of the parameters involved in ejector operation these tests have been performed with no secondary stream which greatly simplifies the test bench operation in the first instance.

Tests were performed by maintaining the primary conditions constant in terms of pressure and subcooling. The discharge pressure at the diffuser exit is varied over a range. Figure 4 shows a typical result obtained under these conditions. Mass flow rate is represented in terms of the ejector outlet pressure with primary stream inlet pressure as a parameter. Three such pressure values, corresponding to $T_{\text {prim-sat }}=35,40$ and $45^{\circ} \mathrm{C}$, together with a $5^{\circ} \mathrm{C}$ subcooling were used.

The usual variation tendency of the mass flow rate is generally observed in that, when primary inlet pressure increases, the mass flow rate increases accordingly. Moreover, when reducing the ejector outlet pressure, mass flow rate increases up to the point where it levels off to a plateau characterizing the critical conditions. The ejector critical condition in this case corresponds to the beginning of this plateau, and tends to increase with the primary stream inlet pressure. However no major difference is observed in the expansion as $P_{\text {prim }} / P_{\text {crit }} \approx 2.9$ for $T_{\text {prim-sat }}=40$ and $45^{\circ} \mathrm{C}$. Since no ejector internal information is available (only inlet and outlet values are measured), it may be anticipated that expansion at the nozzle outlet is likely to be higher, some compression is expected in the mixing chamber and the diffuser.

Figure 4 also indicates that for the lower primary stream pressure tested and corresponding to $\left(T_{\text {prim- }}\right.$ $s_{s a t}=35^{\circ} \mathrm{C}$ ), the critical conditions were not achieved. Assuming that the expansion is of the same order of magnitude as for the other two conditions tested (i.e. 40 and $45^{\circ} \mathrm{C}$ ), then the critical pressure should be anywhere below $300 \mathrm{kPa}$. Unfortunately, the current test bench specifications do not extend this pressure range below this value.

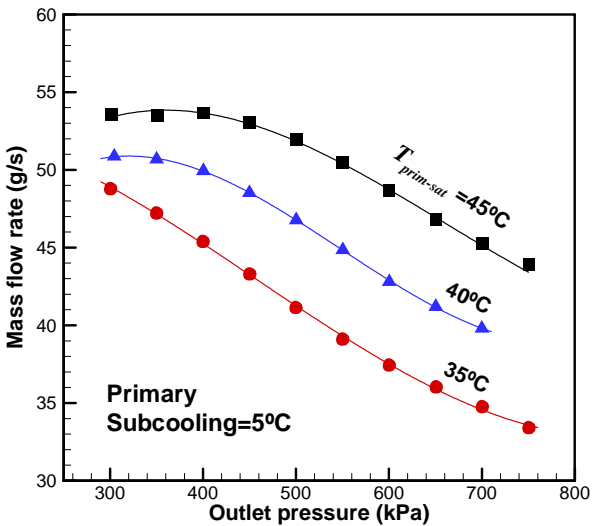

Fig. 4. Typical result from the test bench.

\section{RESULTS AND DISCUSSION}

The first set of results has been used for model validation of the critical two-phase flow in the ejector nozzle. Then, numerical simulations under different conditions and an analysis of the predictions were performed, on the impact of slip flow on the design and operation of ejectors in the context of two-phase flow.

\subsection{Modeling Validations}

The data used in the validation were both collected from the literature and generated in house from an experimental test bench built from the purpose. Data from the literature was limited and relate to the flow of saturated liquid at the nozzle inlet. Two fluids were only available: $\mathrm{CO}_{2}$ and water.

Data from the test bench was obtained for R134a at different subcooling levels at the ejector inlet and no secondary stream.

Table 3 summarises the conditions for different series of critical flow measurements performed on the test bench for validation purposes.

Table 3 Test bench data for validation.

\begin{tabular}{|c|c|c|c|c|}
\hline Run & $\begin{array}{c}P_{\text {prim }} \\
(\mathrm{kPa})\end{array}$ & $\begin{array}{c}T_{\text {prim-sat }} \\
\left({ }^{\circ} \mathrm{C}\right)\end{array}$ & $\begin{array}{c}\Delta T_{\text {sub }} \\
\left({ }^{\circ} \mathrm{C}\right)\end{array}$ & $\begin{array}{c}P_{\text {dif }} \\
(\mathrm{kPa})\end{array}$ \\
\hline $\begin{array}{c}\text { Series 1 } \\
\text { (Fig. 6) }\end{array}$ & $\begin{array}{c}770 \\
1016\end{array}$ & $\begin{array}{c}30 \\
40\end{array}$ & 5 & 300 \\
\hline $\begin{array}{c}\text { Series 2 } \\
\text { (Fig. 7) }\end{array}$ & 1355 & 56.7 & $0.7-45$ & 300 \\
\hline
\end{tabular}

\subsubsection{Isolated nozzle flow case}

The first validation step has been performed with the data available in the literature for a standalone nozzle with an isentropic efficiency of 0.85 .

Table 4 below shows in its first two columns, experimental data of the critical mass flux (Henry \& Fauske 1971) in a nozzle working on saturated liquid $\mathrm{CO}_{2}$ for several inlet pressures. The next three columns of this table show the percentage discrepancy of the predictions with three different theoretical models. 
Table 4 Validation with saturated $\mathrm{CO}_{2}$ at nozzle inlet

\begin{tabular}{|c|c|c|c|c|}
\hline & \multirow{2}{*}{$\begin{array}{c}G_{t} \\
P_{0}\end{array}$} & $\begin{array}{c}|c| \\
\text { Experiment } \\
(\mathrm{MPa})\end{array}$ & \multicolumn{3}{|c|}{ Model Error (\%) } \\
\cline { 3 - 5 } & $\left(\mathrm{Hg} / \mathrm{m}^{2} \mathrm{~s}\right)$ & HEM & Moody & Eq.23 \\
\hline 4.16 & 67695.8 & 63.9 & 54.5 & 25.9 \\
\hline 4.48 & 65611.0 & 61.1 & 51.7 & 21.4 \\
\hline 4.84 & 61771.0 & 56.9 & 47.2 & 14.1 \\
\hline 5.20 & 56394.9 & 50.9 & 40.7 & 3.7 \\
\hline 5.57 & 51238.1 & 44.1 & 33.2 & -8.1 \\
\hline
\end{tabular}

Figure 5 shows a representation of the critical mass flux in a nozzle, based on the experimental values of (Yoon et al. 2006). The fluid is water at saturation at different stagnation inlet pressure conditions. Simulated results of these conditions and with the same models as in the previous case are represented as well. The same tendency is observed in that the predicted results underestimate the experiments. It can also be pointed out that the new model formulated by Eq. (23) shows less discrepancy with the experimental data (20 to $27 \%$ approximatively) in comparison with the previous models of Moody and HEM.

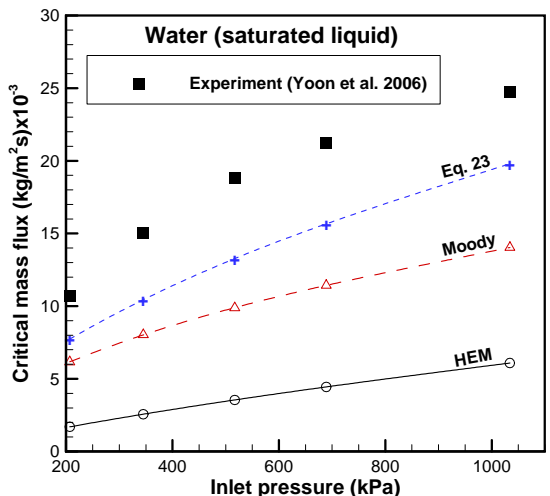

Fig. 5. Validation with saturated water at nozzle inlet.

\subsubsection{Ejector flow case}

In order to extend the validation based on data from the literature and obtained with saturated liquid at the inlet of a standalone nozzle, further measurements were performed on a dedicated ejector test bench built in house. Data in a range of conditions including primary pressure and subcooling variation were generated. Subcooled liquid R134a was fed in the ejector inlet at pressures varying in the $770-1555 \mathrm{kPa}$ range and the ejector was operated with no induced flow. At the diffuser exit, the pressure was maintained constant at 300 $\mathrm{kPa}$.

In this case, all calculations were performed for the entire ejector, including the primary nozzle, the mixing chamber and the diffuser. The wall friction in the mixing tube has been taken into account by the Darcy equation (Ameur et al. 2014). In the nozzle and the diffuser, isentropic efficiency coefficients were employed with values of $\eta_{\text {prim }}=0.85$ and $\eta_{d i}=0.3-0.6$, respectively as a result of experimentally based calibration. These values are lower than those usually encountered in single phase ejector studies but confirm globally those proposed by many researchers (Ersoy and Sag 2014; Lawrence and Elbel 2014) in the context of ejector two-phase flow analysis.

Figure 6 includes three graphic representations for mass flow rate, exit quality and pressure respectively. Experimental values are obtained for three test conditions of inlet pressure $(770,1016$ and $1318 \mathrm{kPa})$ corresponding to saturation temperatures of 30,40 and $50^{\circ} \mathrm{C}$, respectively. Inlet subcooling is maintained constant at $5^{\circ} \mathrm{C}$. Diffuser outlet quality is estimated by means of an energy balance on the ejector. The predictions of the three models selected are also represented on these graphics for comparison.
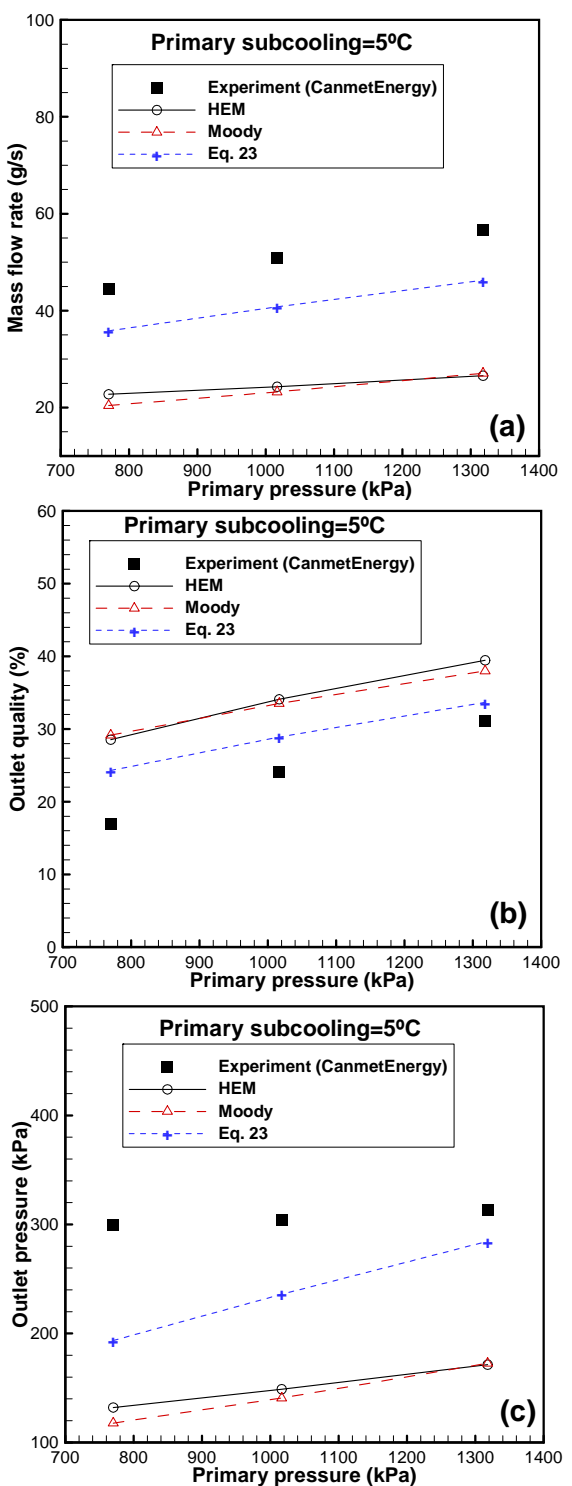

Fig. 6. Validation with test bench R134a data at different primary pressures: (a) mass flow rate (b) outlet quality (c) outlet pressure. 
HEM and Moody models sensibly predict the same results which are widely apart from the experiments. On the other hand, Eq. (23) model generates results much closer to experimental values in the order of $18-20 \%$ of discrepancy on the flow rates, $8-44 \%$ on the quality and $8-35 \%$ on the pressure at the ejector outlet. Note the sensible improvement of the latter model with the primary pressure increase, except for the mass flow rate discrepancy which remains relatively constant (Fig. 6c).

This dependence on the primary pressure may be due to the fact that the ejector outlet pressure is imposed in the experiments. If this pressure were allowed to vary, then by changing the primary pressure, the pressure at the ejector exit would vary in order to accommodate the critical flow condition. It is precisely what the models were programmed to do. In this way, going back to Fig. 4 , it can be easily seen that for the lowest primary pressure corresponding to $35^{\circ} \mathrm{C}$, the simulation was performed for the critical conditions but the experimental value does not correspond to this condition. The critical condition in this case can only be achieved with an ejector outlet pressure less than $300 \mathrm{kPa}$.

Figure $6 \mathrm{~b}$ depicts the experimental outlet quality variation and its overestimated prediction by the models. This maybe partly due to the fact that phases' thermal non-equilibrium is not modeled. According to some previous works, nozzles below about $10 \mathrm{~cm}$ in length as is the case for the currently tested ejector, there is no sufficient time for the flow to transfer heat between phases, so that thermal equilibrium can be established. Some delay in the onset of fluid flashing is generally observed (Wallis 1980; Westman 2008).

Figure 7 presents three graphical distributions of mass flow rate, outlet quality and pressure in terms of subcooling for a fixed primary inlet pressure. Here again experimental data from the test bench, as well their respective simulations are represented for comparison. A primary inlet pressure of 1555 $\mathrm{kPa}$, corresponding to the saturation temperature of $56,7^{\circ} \mathrm{C}$ is imposed. It is worth noting that Moody's model could be used only for a limited subcooling of $4.5^{\circ} \mathrm{C}$. In the range of up to $30^{\circ} \mathrm{C}$ subcooling, the new model (Eq. 23) offers the best predictions of the experimental data. Beyond $30^{\circ} \mathrm{C}$, the HEM model fairly predicts mass flow rates and pressure.

\subsection{Results Comparison: HEM vs Slip Models}

In the paragraphs of the previous section it has been demonstrated that slip flow has a substantial impact on the prediction accuracy of the two-phase critical flow. Recall that new model (Eq. 23) has been shown previously to represent validation data fairly well for the case of the nozzle alone, and for the ejector with no induced flow.

It is proposed here to apply this model as well as the HEM which serves as a reference on a typical example, in order to evaluate the impact of phase slip on two-phase ejector design.

The operational conditions chosen for the ejector are those approaching realistic refrigeration practice. The ejector design is for a mechanical compression refrigeration cycle under the following conditions: the primary and secondary inlet temperatures of the ejector correspond respectively to the condenser and evaporator outlets in the refrigeration cycle (see Fig. 1b). Saturated liquid, at various temperature $\left(35-55^{\circ} \mathrm{C}\right)$, is used at the primary inlet. Saturated vapour at $0^{\circ} \mathrm{C}$ is assumed to be drawn with an entrainment ratio of 0.4 .

The isentropic efficiency coefficients in the ejector nozzles and the diffuser are those used in the validation exercise and the mixing factor is taken to be $\varphi_{m}=0.96$. The computations are then performed with no slip (HEM model) and with slip (Eq. 23 in new model).
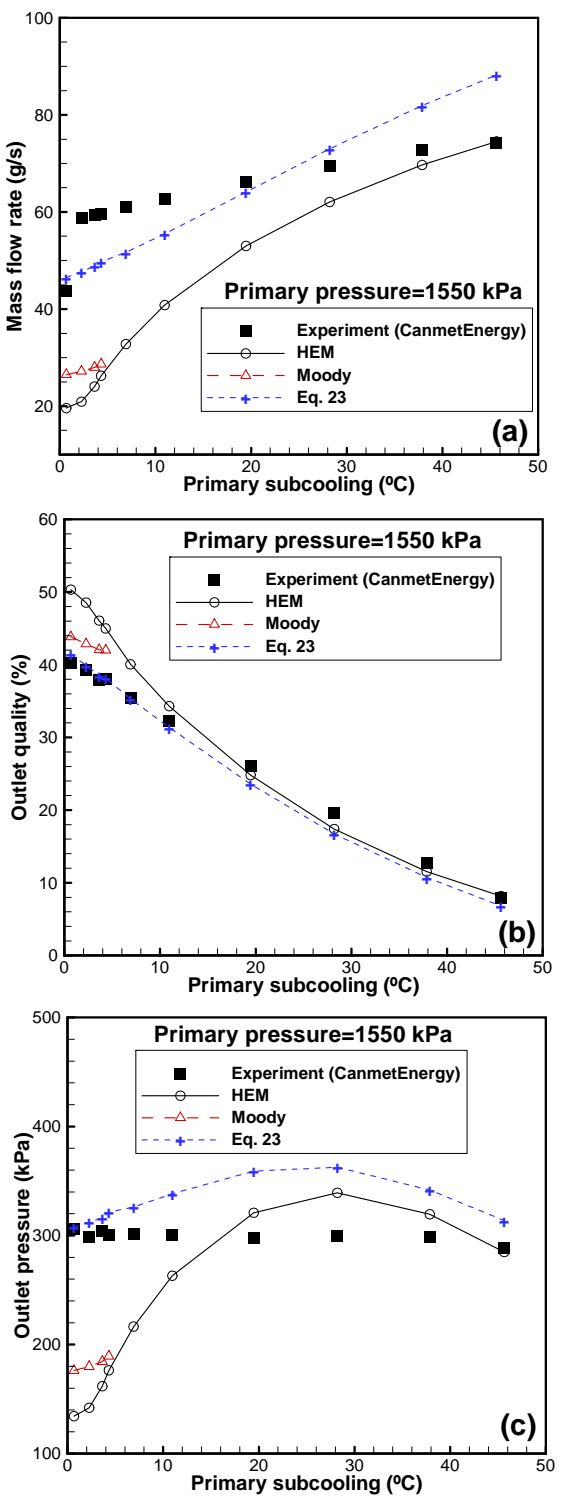

Fig. 7. Validation with R134a test bench data and different subcooling inlet: (a) mass flow rate (b) outlet quality (c) outlet pressure. 
Figure 8 represents two graphics for the compression ratio and the throat diameter of the primary nozzle in the same conditions as indicated. Two refrigerants are tested (R134a and Propane) under different saturation pressure and temperature of the primary liquid stream inlet. Computations in both cases are performed based on the new (slip) and the HEM (no slip) models which are then plotted respectively on the $\mathrm{Y}$ and $\mathrm{X}$ axes of the Figure.

Figure 8 a shows a relatively modest compression ratio $(\leq 1.16)$ irrespective of the primary flow conditions. This result is typical of the two-phase ejector compression capability and such tendency confirms most of several previous works on the subject. Equation (23) is shown to predict a better compression ratio than HEM and the prediction gap between these two procedures is of the order of 13 to $23 \%$. The fluid type does not show to have much impact on the result.

The throat diameter for the primary nozzle is shown in Fig. 8b. It is first worth noting that when the primary pressure and temperature conditions increase, the throat diameter decreases irrespective of the model used. When the primary pressure in the nozzle increases, the flow density and generally the flow velocity and as a consequence, the mass flux increase as well. Since the primary mass flow rate is maintained constant, then the throat diameter decreases.
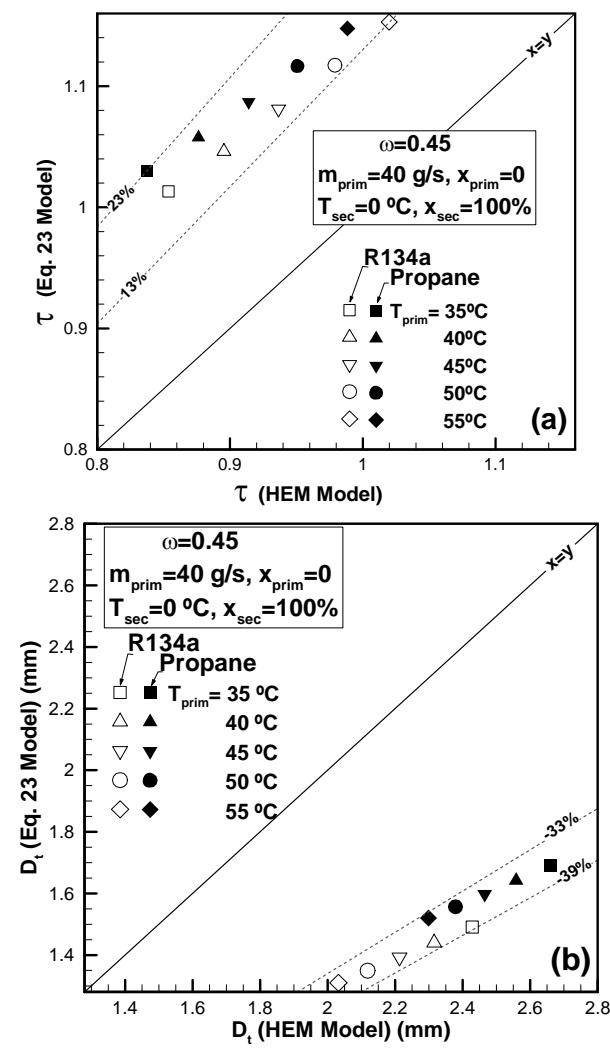

Fig. 8. HEM Model vs Eq. (23) Model comparison: (a) compression ratio and (b) throat diameter.
As for the impact of the slip ratio on the throat size, it can be observed that the prediction difference between the two models ranges between 33 and $39 \%$. Sizes for propane are slightly larger than those for R134a due to their properties but has no effect on the models predictions difference.

\section{CONCLUSION}

The criterion to determine the critical parameters at the ejector nozzle throat generally makes use of the Mach number. For two-phase flow nozzles, this approach becomes problematic and a new condition relying on flux maximisation is proposed. Further the new model takes care of the mechanical non equilibrium between the liquid and vapour phases. In the range of inlet subcooling up to about $30^{\circ} \mathrm{C}$, this measure improves considerably the prediction of the critical flow in comparison with established models such as Moody and HEM. Beyond this value of subcooling, HEM predictions fairly improve.

Available data in the literature about the critical flow in two-phase nozzles is mainly for water in nuclear applications. However data generated with $\mathrm{R} 134 \mathrm{a}$ on an ejector test bench built in house has allowed extending the validation to a wide range of conditions and parameters.

The experimental results generated for validation purposes were all obtained for an ejector operating with no induced flow in the first instance in order to better figure out the primary choking phenomenon. Induced flow with the same ejector working conditions will be dealt with in a future work.

Last but not least, it has been shown that the mechanical non equilibrium in two-phase ejector modeling has a considerable impact on the design. For a typical refrigeration application and the corresponding ejector inlet conditions, the impact of the slip ratio between liquid and vapour phases is in the range of 13 to $23 \%$ on the compression ratio. The consequences on the nozzle geometry and throat size are even higher with 33 to $39 \%$ disparity on the throat diameter, independently from the refrigerant used.

\section{ACKNOWLEDGEMENTS}

This project has been funded by PERD, a program of Natural Resources Canada for R-D.

\section{REFERENCES}

Ameur, K., Z. Aidoun, and M. Ouzzane (2014). Modeling and numerical approach for the design and operation of two-phase ejectors. Applied Thermal Engineering, In Press, Corrected Proof.

Attou, A., and J. M. Seynhaeve (1999). Steady-state critical two-phase flashing flow with possible multiple choking phenomenon. Journal of Loss Prevention in the Process Industries, 12, 335345. 
K. Ameur et al. / JAFM, Vol. 9, Special Issue 2, pp. 213-222, 2016.

Banasiak, K., and A. Hafner, (2011). 1D Computational model of a two-phase R744 ejector for expansion work recovery. International Journal of Thermal Sciences, 50, 2235-2247.

Collier, J. G., and J. R. Thome (1994). Convective Boiling and Condensation. (3rd ed., p. 640). Oxford University Press.

Domanski, P. A. (1995). Theoretical evaluation of the vapor compression cycle with a heat exchanger, economizer, and ejector. Technical report, USA, NISTIR5606.

Ersoy, H. K., and N. B. Sag (2014). Refrigeration System using a Two-phase Ejector as an Expander. International Journal of Refrigeration, 43, 97-110.

Henry, R. E., and H. K. Fauske (1971). The TwoPhase Critical flow of One-Component Mixtures in Nozzles, Orifice, and Short Tubes. J. Heat Transfer, 93(2), 179-187.

Kornhauser, A. A. (1990). The Use of an Ejector as a Refrigerant Expander. International Refrigeration and Air Conditioning Conference, Purdue University, paper 82.

Lawrence, N., and S. Elbel (2012). Experimental and Analytical Investigation of Automotive Ejector Air-Conditioning Cycles Using LowPressure Refrigerants. International Refrigeration and Air Conditioning Conference, Purdue University, paper 1169.

Lawrence, N., and S. Elbel (2014). Experimental investigation of a two-phase ejector cycle suitable for use with low-pressure refrigerants $\mathrm{R} 134 \mathrm{a}$ and R1234yf. International Journal of Refrigeration, 38, 310-322.

Liu, F., and E. A. Groll (2008). Analysis of a Two
Phase Flow Ejector For Transcritical $\mathrm{CO}_{2}$ Cycle. International Refrigeration and Air Conditioning Conference, Purdue University, paper 924 .

Liu, F., and E. A. Groll (2013). Study of ejector efficiencies in refrigeration cycles. Applied Thermal Engineering, 52(2), 360-370.

Michaelides, E. E., and K. L. Zissis (1983). Velocity of sound in two-phase mixtures. Int. J. Heat \& Fluid Flow 4(2), 79-84.

Moody, F. J. (1965). Maximum flow rate of a single component, two-phase mixture. Journal of Heat Transfer, 87(1), 134-141.

Nakagawa, M., T. Matumi, H. Takeuchi and N. Kokubo (1996). Mixing of the confined jet of mist flow. JSME International Journal, 39(2) 381-386.

NIST (2007). Thermodynamics and Transport Properties of Refrigerants and Refrigerant Mixtures-REFPROP, Version 8.

Wallis, G. B. (1980). Critical two-phase flow. Int. J. Multiphase Flow 6, 97-112.

Weisman, J., and A. Tentner (1978). Models for estimation of critical flow in two-phase systems. Progress in Nuclear Energy, 2, 183197.

Westman, M. A. (2008). Computation of nozzle flow capacities for superheated steam, subcooled water, and saturated steam/water mixtures. Journal of Loss Prevention in the Process Industries, 21(6), 567-578.

Yoon, H. J., M. Ishii and S. T. Revankar (2006). Choking flow modeling with mechanical and thermal non-equilibrium. International Journal of Heat and Mass Transfer, 49, 171-186. 